\title{
On Having a Good
}

\section{Citation}

Korsgaard, Christine M. 2014. “On Having a Good." Philosophy 89 (03) (July): 405-429. doi:10.1017/s0031819114000102. http://dx.doi.org/10.1017/S0031819114000102.

\section{Published Version}

doi:10.1017/S0031819114000102

\section{Permanent link}

http://nrs.harvard.edu/urn-3:HUL.InstRepos:12559503

\section{Terms of Use}

This article was downloaded from Harvard University's DASH repository, and is made available under the terms and conditions applicable to Open Access Policy Articles, as set forth at http:// nrs.harvard.edu/urn-3:HUL.InstRepos:dash.current.terms-of-use\#OAP

\section{Share Your Story}

The Harvard community has made this article openly available.

Please share how this access benefits you. Submit a story.

\section{Accessibility}




\title{
On Having a Good
}

\author{
Christine M. Korsgaard \\ Harvard University
}

\begin{abstract}
In some recent papers I have been arguing that the concept 'good-for' is prior to the concept of 'good' (in the sense in which final ends are good), and exploring the implications of that claim. One of those implications is that everything that is good is good for someone. That implication seems to fall afoul of our intuitions about certain cases, such as the intuition that a world full of happy people and animals is better than a world full of miserable ones, even if the people and animals are different in the two cases, so that there is no one for whom the second world is better. Such cases tempt people to think that there must be impersonal goods, and that what it means to say that something is good for you is that you are the one who 'has' some impersonal good. In this paper, I argue that if we approach things in this way, it is impossible to say what the 'having' consists of, what relation it names. This leads me to a discussion of various things we do mean by saying that something is good for someone, how they are related to each other, and what sorts of entities can 'have a good.' Finally, I explain why we think that a world full of happy people and animals is better than a world full of miserable ones, even if the people and animals are different in the two cases.
\end{abstract}




\section{Introduction}

You are the kind of entity for whom things can be good or bad. This is one of the most important facts about you. It provides you with the grounds for taking a passionate interest in your own life, for you are deeply concerned that things should go well for you. Presumably, you also want to do well, but that may be in part because you think that doing well is good for you, and that your life would be impoverished if you did not. ${ }^{1}$ But even if your interest in doing well is completely independent of any reference to your own condition, it probably depends on the thought that there are other entities, entities who are dependent upon you or affected by you, for whom things can be good or bad. It is only because there are entities like you, entities for whom things can be good or bad, that anything is important at all. If there were no entities for whom things can be good or bad, nothing would matter.

What I have just said may sound rather obvious, but in fact, it is controversial. Many philosophers believe that things can be good or bad without being good or bad for anyone or anything in particular. They think, for instance, that the world is a better place if it is full of happy people and animals than if it has no inhabitants at all, or only miserable ones. Or they think that it is better if wealth is distributed more equally than if some people are very rich and some very poor. If things like these are true, you might suppose, then there must be

\footnotetext{
${ }^{1}$ Actually, it follows from the view I defend in this paper that it is necessarily true that doing well is good for you, or at least that you cannot achieve your good without doing well. See section 5 .
} 
what are sometimes called 'impersonal' goods. Then you will probably think it is important that such goods should be realized, even though there is no one for whom they are good.

What I have just said may seem puzzling. Isn't it better if the world is full of happy people and animals, because it is better for those people and animals? And isn't it better if wealth is distributed equally, because it is better for the people who would otherwise be poor? The trouble with the first of those claims - that the world is better if it is full of happy people and animals because it is better for those people and animals - is that it is unclear that the world would be the worse for those people and animals, if they did not exist at all. Are all of the people and animals who never existed, and never will, in an unfortunate condition? Is that a bad thing for them? What a miserable place the world must be, if that is the case! But surely, you will reply, it is better if the world is full of happy people and animals than of miserable ones? But for whom is it better? If we are comparing two worlds containing the same inhabitants, in one of which those inhabitants are miserable and in one of which they are happy, the second world is clearly better for them. But suppose we are not comparing two worlds with the same inhabitants. If you are miserable, would it better for you if you were replaced by someone who is not? As for the second claim, of course it is better for the people who would otherwise be poor if wealth were distributed more equally. But by the same token, it would be worse for the people who would otherwise be rich. ${ }^{2}$

${ }^{2}$ This may be false, of course: it may be better for each and every one of us to live in a world where wealth is more equally distributed. Being wealthier than others may corrupt your character so that you are less capable of genuine happiness, for instance. Or if you are good enough to be happy, knowing that you have more than your share may make you unhappy. But in that case equal distributions would be better for individuals, and the example would 
It seems, then, difficult to explain why we are tempted to think that a world full of happiness is better than a world full of misery, or that equitable distributions of wealth are better than lopsided ones, if we hang on to the intuition that things are only good or bad because they are good or bad for someone. On the other hand, it seems strange to suppose that these things matter, if there is no one to whom they matter.

There is another problem as well. Suppose things are good or bad independently of any entities for whom they are good or bad: that is, suppose that the notion of 'good' is conceptually prior to the notion of 'good-for'. ${ }^{3}$ Then what does it mean to be an entity for not, after all, pose a challenge to the idea that things must be good or bad for someone if they are good or bad at all.

${ }^{3}$ Many people seem to think that there are both personal and impersonal goods, and that there is no conceptual priority relation between them. I think this is a non-starter. Why do we call them both by the same name? Is it because it is impersonally good that the personal goods should be realized? If that is not always so - and presumably, it would not be - then why do we call the personal goods 'good' in those cases where it is not? One might adopt what Tim Scanlon calls a buck-passing theory of the good, and then try to argue that whether the good is personal or not depends on whether the reasons are personal or not. (See T.M. Scanlon, What We Owe to Each Other (Cambridge: Harvard University Press, 1998), Chapter 2, especially p 97ff.) But in my view, the question what it means to 'have' a reason gives rise to problems that are parallel to those that arise from the question what it means to 'have' a good. Later I will explain why I think 'having a good' is prior to the existence of 'goods.' Kantians believe that you have a reason when you have made something your maxim. In that case the condition of 'having a reason' is also prior to the existence of 
whom things can be good or bad? Presumably, it means that you stand in some important relation to the goodness or badness of certain things, but what relation, exactly, is it? It cannot be simply that you are aware of these goods and evils, or perceive them, and appreciate their good or bad character. For even if the poor are very generous-minded, and are glad to think of the happy condition of the rich, they seem to stand in a different relation to the happy condition of the rich than the rich themselves do.

In order for something to be good for a certain person, you will want to reply, he has to be the one who has it. But that just raises the same question again. What relation are we talking about, when we talk about this 'having? ${ }^{4}$ The strange fact that we talk about moral matters in terms borrowed from economics - 'value,' 'obligation,' 'owes,' and so on - may lull us into supposing that we have some clear notion of ownership to work with in this case. But the notion of property-ownership will not help us out here, for to say that something is your property is to say that you may use it or enjoy it and that no one else may use it or enjoy it without your permission. But this is not what we mean when we say that your happiness is your own good. For even though the happiness of the rich is the good of the rich and not of the poor, the generous-minded among the poor are certainly free to enjoy the happiness of the rich if they can, and do not need the rich's permission for that.

'reasons.' For some relevant discussion, see my 'Valuing Our Humanity', §2, English version forthcoming. The paper is available in Spanish translation by Dulce María Grande in Signos Filosoficos, No. 26, July-December 2011.

${ }^{4}$ See Christine M. Korsgaard, The Sources of Normativity (Cambridge: Cambridge University Press, 1996), §4.3.3, 146-147. 
There is a question, then, about what it means to have a good - to be the kind of being for whom things can be good or bad. There is also a question about which things can be the kind of entity for whom things can be good or bad. After all, one way out of the dilemmas I've just been discussing would be to suppose that something like 'containing happy people and animals' could be good for the universe itself, or, perhaps more plausibly, that equitable distributions could be good for the community. But if this way out of the dilemma does not work, or if it does not seem to correctly capture our reasons for favoring those things, then there are also questions about what, if anything, does explain why we favor those things. These are the questions I will investigate in this paper: questions about what it means to have a good, what kinds of entities can have one, and how we can explain those cases in which things seem to be good or bad without being good or bad for anyone in particular.

\section{Why Having a Good Must Be Prior to Good ${ }^{5}$}

I will begin from the question what it means to be the kind of entity for whom things can be good or bad. Essentially there are two possible views about this; in this section I will consider the first. The first view, which I have already mentioned and cast some doubt on, holds that some things are good or bad independently of their goodness or badness for anyone or anything in particular. Then to be the kind of entity for whom things can be good

\footnotetext{
${ }^{5}$ For another version of the argument of this section see Christine M. Korsgaard, 'The Relational Nature of the Good', forthcoming in Oxford Studies in Metaethics, Volume 8, ed. Russ Schafer-Landau (Oxford: Oxford University Press, 2013.
} 
or bad is to be capable of standing in some particular relation to certain good or bad things. Focusing on aesthetic cases can make this option initially seem tempting. La Traviata or Van Gogh's Starry Night or the Taj Mahal are good things, and to be the kind of entity for whom these things can be good or bad is to be the kind of entity who is capable of appreciating exactly that fact about them. Because you are capable of appreciating aesthetic value, exposure to beauty to is good for you, while having ugliness thrust upon you is bad. Because rabbits and squirrels are not capable of appreciating aesthetic value, or anyway not of the kind in question, operas and paintings and architectural masterpieces are nothing to them. The rabbit can appreciate the flavor and texture of a carrot, or the squirrel that of a nut, so these things kinds of things can be good for such creatures. But isn't the experience of appreciation or enjoyment itself also a good thing for the creature who is capable of it? After all, isn't it better to enjoy than to suffer, or to appreciate than to be repulsed? But is that because a creature who is capable of appreciating things is also capable of appreciating his own appreciation, or enjoying his own enjoyment? But then are these second-order appreciations and enjoyments also good for the creature, and if so, what makes them so? There is clearly no point in starting off on that endless regress. But that leaves us stuck where we were: if the capacity to appreciate or enjoy something is what makes it good for you, what makes appreciation and enjoyment themselves good for you?

We can see a pattern here. Many people find it natural to suppose that what makes something good for you is that it makes you happy. But they also suppose that your own happiness is a good thing for you. For it is surely better for you to be happy than sad. Is that because being happy makes you happy? This little conundrum may be what drives people to 
the ownership theory that I mentioned earlier: happiness, they say, is a good thing in itself, and what makes a bit of happiness good for you is that it is yours.

But, as I argued before, we then need to explicate what it means to say that the happiness is yours. What relation is that? As I said before, it is not the ordinary ownership relation, the relation of standing in normative control over the use of a thing. It also seems odd to analogize happiness to property for other reasons. Could there be unowned bits of happiness lying around, the way there were once unowned bits of real estate? ${ }^{6}$ Following John Locke, shall we say that you may lay claim to a piece of happiness, only if you make

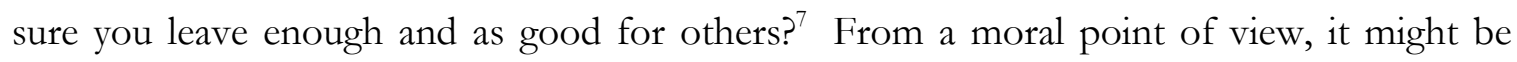
pleasant to believe that, but declining a piece of happiness is not a way of ensuring that it is there for someone else. ${ }^{8}$ All happiness is someone's happiness: the idea of happiness is an inherently relational idea. To say that your happiness is yours is not to say that you stand in

${ }^{6}$ I've worded it this way because, strictly speaking, there is no property that is not someone's property, any more than there is happiness that is not someone's happiness. Property is a relational notion. But it does in a sense name a relation between two independently existing things.

${ }^{7}$ John Locke, Second Treatise of Government (Indianapolis: Hackett Publishing Company, 1980), Chapter V, paragraph 33, 21.

${ }^{8}$ Declining some thing that would make you happy can be a way of ensuring that it is there for someone else, of course, and if it would make that other person happy then this is a case where you can trade in your happiness to secure that of someone else. But that really is a very different point: it does not show that happiness is a good thing in itself like a piece of property that becomes good for you when you claim it for your own. 
a special relation to some piece of happiness that would otherwise be free-floating or belong to someone else. And if happiness is the good, that means that to say that something is good for you is not to say that you stand in a special relationship to something good that would otherwise be free-floating, or belong to someone else.

Now of course some people assert, and some deny, that happiness is the good. If this debate is about anything, the term 'happiness' must refer to something more specific than just 'whatever is good for someone.' Many people think it refers in particular to the quality of our experiences, and has something to do with their being pleasant rather than painful. Then people who deny that happiness is the good are protesting against the idea that all that matters is the quality of our experiences, while the people who think happiness is the good are convinced that unless we experience something, at least indirectly, it can have no impact on us whatever.

But we do not need to enter this familiar debate, for everything I said before about happiness can be said about pleasure. We can claim that what makes something good for you is that it provides you with pleasant experiences. But that cannot be what makes pleasant experiences themselves good for you. That little conundrum may drive us into an ownership theory of pleasure: pleasure is a good thing, and what makes it good for you is that it is yours. But then again, we have to ask what the ownership consists in. Here the tempting answer will be that you are the one who experiences it. But again, it is not as if there is some unexperienced pleasure lying around, and being the one who experiences it is laying some sort of a claim to it.' All pleasure is someone's pleasure: the idea of pleasure is

\footnotetext{
${ }^{9}$ If someone thanks you for doing something, and you reply, 'The pleasure is all mine', you are not saying something crassly selfish.
} 
an inherently relational idea. To say that your pleasure is yours is not to say that you stand in a special relation to some piece of pleasure. If pleasure were the good, that would mean that to say that something is good for you is not to say that you stand in a special relationship to something good. And while we are at it, experience is relational too: so to say that you are the one who has a certain experience is not to say that there is some experience to which you stand in a special relation. So what makes something your good cannot be that you are the one who experiences it.

I have been arguing that to say that something is your good cannot be to say that there is some good to which you stand in a special relation, a relation at which we gesture by saying that you are the one who 'has' that good. I can imagine someone thinking that he can show that this form of argument must be wrong. Take the following comparison: If Aristotle is right in arguing that a dead hand is not really a hand at all, then every real hand must be someone's hand. ${ }^{10}$ Yet, surely, we can still say that what makes something your hand is that you are the one who has it? But, no, actually we cannot, for there is still the problem of what the right kind of 'having' consists in. We can imagine all kinds of macabre ways in which you

${ }^{10}$ Aristotle, Metaphysics 7.10 1035b23-25: 'for it is not a finger in any state that is the finger of a living thing, but a dead finger is a finger only homonymously.' Politics 1.2 1253a20-25: 'if the whole body be destroyed, there will be no foot or hand, except homonymously, as we might speak of a stone hand; for when destroyed the hand will be no better than that.' On the Soul 2.1 412b20-22: 'when seeing is removed, the eye is no longer an eye, except in name no more than the eye of a statue or a painted figure.' The translations are from The Complete Works of Aristotle: The Revised Oxford Translation, edited by Jonathan Barnes. Princeton: Princeton University Press, 1984. 
could 'have' a hand that would not make it yours in the sense we want here. Only when we hit on the right relation - the right kind of 'having' - would the hand really be, by Aristotle's criterion, a hand at all. ${ }^{11}$ What this shows is that the condition of 'having a hand' is prior to the hand itself. So the important point here is not merely that everything that is good must be someone's good: it is that everything that is good must be related to someone in a particular way before it can really be something good at all. That shows that the condition of 'having a good' is prior to the good itself. That is why I am claiming that someone's being in a condition of having a good, or something's being good for someone, is prior to the good itself.

\section{Two Senses of Good for You}

I started from the claim that there are two possible views about what it is to be an entity who has a good. The first holds that some things are good or bad independently of their goodness or badness for anyone or anything in particular, and that to be the kind of entity for whom things can be good or bad is to be capable of standing in some particular relation to those good and bad things. We have now seen what is wrong with that theory. This brings us to the other view, which is that the notion of good-for is more fundamental than the notion of good, and that for something to be good is essentially for it to be related to someone in a particular way.

\footnotetext{
11 'For it is not a hand in any state that is a part of man, but the hand which can fulfill its work, which therefore must be alive; if it is not alive, it is not a part.' Aristotle, Metaphysics $7.10,1036 \mathrm{~b} 30-32$.
} 
But before I can say what that particular way is, I need to distinguish two apparently different things we might mean when we say that something is good for someone. Suppose Alfred and Bertrand are competing for a position, and Alfred gets it. That, we say, is good for Alfred, but bad for Bertrand. To be clear here, I am not imagining that the position is one that Alfred and Bertrand want just because, say, it carries a salary. I'm imagining it as a coveted position, one in which a person might engage in worthwhile activity and distinguish himself at the same time, a position that might be the basis of a good life. When we use 'good for Alfred' in this kind of case, we are using it in the way I have been using it up until now in this paper. We mean that getting the position will be a source of pleasure for Alfred or will make him happy, or that it is part of things going well for him, or that it is part of what makes his life a good one for him. We mean to put Alfred's getting the position in the same category of things in which hedonists put pleasure and eudaimonists put happiness, the category of things that are good for their own sake or things that constitute such goods or contribute to them. To say that things are good in this sense is to mark their relation to things we might decide to pursue for their own sakes. So although the term isn't perfect for my purposes, I am going to call this the 'final' sense of good-for. ${ }^{12}$

\footnotetext{
12 'Final' is a slightly misleading name, since it turns out that both ends and means can be good in the way that I am trying to identify here. As will become clear, I mean goods that seem or can seem worthy of pursuit from the agent's point of view, whether for their own sake or for the sake of something else, something that is a final good in the more ordinary sense. Nevertheless, in what follows I will sometimes use 'final' in the more ordinary sense, to refer to goods sought for their own sake. I don't think this will cause any confusion.
} 
On the other hand, when Alfred's mother informs him that broccoli is good for him, she does not mean to put broccoli in the same category in which hedonists put pleasure and eudaimonists put happiness. She does not mean that eating broccoli is part of the human good in the way that aesthetic experiences, happy marriages, and lives full of accomplishment and pleasure are part of the human good. She does not mean that either broccoli itself, or eating broccoli, is a final good. It is possible that that is true, I suppose, but nevertheless, it is not what she means. She means, more or less, that broccoli is healthy, and that it will make Alfred healthy. I am going to call this, for now anyway, the 'motherly' sense of good-for, as opposed to the final sense.

Now you may be tempted to think that the difference here is just a matter of degree, a question of how directly the thing benefits Alfred. Actually, there are two ways to hold this view. A crude sort of hedonist thinks that pleasure, thought of as some particular kind of sensation, is the final good, and everything else is related to that final good causally. In that case everything but pleasure itself is instrumental to the final good, and the difference of degree in question here is a matter of instrumental or causal distance. Eating broccoli causes you to be healthy, which makes you capable of engaging in certain other activities, which in turn cause the sensation of pleasure. A less crude hedonist, however, might think that the relationship between pleasure and activity is not one in which the activity causes a certain sensation, but one in which the pleasure is somehow a characteristic of the activities themselves. ${ }^{13}$ Even so, this less crude hedonist might think that the difference between the way in which the pleasurable activities are good for you and the way in which broccoli is good for you is a matter of the directness of the benefit. Dancing a waltz with a handsome

\footnotetext{
${ }^{13}$ See Aristotle's discussions in the Nicomachean Ethics at 7.11-12 and 10.1-5.
} 
partner is the sort of thing that constitutes the good for you directly, while eating broccoli is good for you too but less directly: it promotes your health, which equips you for enjoying such activities as dancing waltzes with handsome partners, as well of course as helping you to ward off pain.

But there are two problems with the idea that what we have here is simply a difference of degree in the directness of the benefit. The first is that the kinds of theories that make this way of thinking seem natural are exactly the ones that landed us in the quagmire we have just left behind: they leave nothing for the claim that pleasure or pleasurable activities or happiness are themselves good for you to mean. On this theory, we would have to identify a final good as the thing that is most directly related to - well, to what? - to your final good, of course - and so we would get stuck in a circle.

So let's grant that the difference between saying that getting the job is good for Alfred in the final sense and saying that broccoli is good for Alfred in the motherly sense is not just a matter of how directly the thing in question benefits Alfred. What then is the difference? You might be tempted to say that even though we have not yet figured out quite what we mean when we say that something is good for Alfred in the final sense, it is still clear enough what we mean when we say that something is good for Alfred in the motherly sense. We mean that it is instrumental - that it promotes some final good that is valued for its own sake. That is what Alfred's mother is saying about eating broccoli.

I don't think that is right, however, and this brings me to the second problem. According to the theory on offer, eating broccoli promotes Alfred's health, and Alfred's health in turn promotes his ability to engage in the kinds of activities that somehow directly constitute his final good. Keep in mind that the question is not merely whether all of that is 
true, but rather, whether that is what Alfred's mother is saying when she says that broccoli is good for him. That's what doesn't seem right to me. For suppose that Alfred's lover has left him to take up with Bertrand, and Alfred is feeling suicidal. 'Eat your broccoli,' his mother urges. 'It's good for you.' According to the theory on offer, Alfred should say, 'No, it isn't. Since all I want to do is die, the benefits of eating broccoli are completely irrelevant to me, or maybe they are even bad, since they will tend to keep me alive.' But of course, that's not what Alfred actually going to say. What he actually is going to say is, 'Yes, but I don't care.'

Perhaps you think this is just because Alfred is not sufficiently reflective, and the use of the phrase 'good for you' to mean something like 'promotes your health' is so well established, idiomatically, that he fails to question the suitability of the claim to his own case. A more philosophical Alfred would say the first thing: that his mother has made a wrong calculation about what will benefit him. But in my view the second Alfred, the more likely Alfred, has got it right. Alfred is not explaining to his mother that she has made an error in calculation. He is declaring that, being in despair, he does not care about himself, and so does not care about what is good for him. 'Good for you' in the motherly sense of 'Broccoli is good for you' does mean something like 'promotes your health', not something like 'indirectly promotes your final good.’

The only problem is that 'promotes your health' is a little too specific, even for the motherly use of the phrase. For one thing, even in the motherly sense, we often generalize the idea to include psychological health, as when we say, 'It is precisely because you are so depressed that it would be good for you to get out and see people more.' Even in the motherly sense, we sometimes generalize the idea even further to include moral and spiritual 
health, as when we say, for instance, 'You have been so successful that it is really good for you to be taken down a peg now and then.'

But the problem is not merely that the proposed definition of the motherly sense of 'good for you' as 'promotes your health' might be taken to be limited to physical health. It is also that - or so I claim - we can use the phrase in the motherly sense to talk about things that are not good by way of promoting, or at least not merely by way of promoting, anything at all. This point is a little harder to motivate, but let me give it a try. For one thing, I think that we sometimes say, in the same spirit as Alfred's mother, that it is good for people to enjoy themselves sometimes, or to contemplate natural beauty, or to go to museums to appreciate art or to learn something about the world they live in. That is to say, we sometimes recommend these things, not as things that would be good for people in the sense of making them happy, but in the sense of being somehow healthy. Yet these things are not mere means that promote some other state.

Well, you may reply, that is no problem. Many things are both means and ends. When we say that these things are good for people in the same spirit in which Alfred's mother says that broccoli is good for Alfred, we mean that they promote people's psychological, moral, and spiritual health, and so are means. But when we say that they are good for people in the spirit in which we said that it was good for Alfred but bad for Bertrand that Alfred got the position, we mean they are also ends. The motherly use of good-for applies to the means to various kinds of health, while the final use of good-for applies to ends, which, as it happens, sometimes coincide with the means to various kinds of health. 
But I don't think it's quite that simple. For consider that in the resulting story, it is good for people to enjoy themselves sometimes, contemplate natural beauty, go to museums to appreciate art and learn something about the world they live in, so that they achieve a state we call 'health,' which in turn promotes their ability to enjoy themselves sometimes, contemplate natural beauty, and go to museums to appreciate art or learn something about the world they live in. What sort of a merry-go-round, you might ask, are we on here?

The answer, of course, is that it is the same sort of merry-go-round that the classical Greek philosophers, at least Plato and Aristotle, thought we were on with respect to the moral virtues. What the practice of moral virtue makes us capable of, according to Plato and Aristotle, is virtuous activity itself. In fact for this very reason, Plato and Aristotle frequently compared moral virtue to health.

This comparison will help us to see that the problem rests in the characterization of health as a means. In The Practice of V alue, Joseph Raz suggests at one point that health is a means to personal survival. ${ }^{14}$ No one survives, of course, but I suppose we could view health as a means to an extended life. Few people, however, wish for an extended life unless they can be assured of a reasonable degree of health. Do we then want health as a means to living a reasonably healthy life? Taking our cue from virtue, we can see that the right thing to say here is not that health is valued as a means to an extended life but rather, that it is valued as the excellence, or the goodness, of your physical life.

\footnotetext{
${ }^{14}$ Raz, The Practice of Value (Oxford: Clarendon Press, 2003), 16. Of course Raz grants that one may value health for other reasons as well. See my commentary on his remarks at 77-81 of that volume for background to the thoughts here.
} 
There are two reasons why this is the right thing to say. One is that it is very nearly a tautology to say that good health will extend your life, and claims about means are not normally tautologies. ${ }^{15}$ Although obviously health does not guarantee the extension of life you can always get hit by a meteorite - we should not call a condition 'healthy' if it did not tend to maintain or extend life. The other is that it explains the pair of judgments I just mentioned - that people try to be healthy in order to extend their lives but only if their lives will be healthy ones. The explanation is simply that people want to extend reasonably good physical lives but do not usually want to extend bad ones unless there is some special reason. For of course health can be a means to something in particular - if you want to survive long enough to finish writing your masterpiece, or to raise a late-born child to adulthood, say but that thought is most natural when you have come to regard your physical life itself as a means to something in particular, to some other aspect of your life. But in the ordinary case, we do not think of health as a means to something, but rather as simply one form of the goodness of your life, namely, the goodness of your physical life. When we generalize the motherly use of 'good for you' to broader forms of life, to the psychological and the spiritual and the moral, then we are talking about the goodness of your life quite generally. In the motherly sense, when we say that something is good for you, we mean that it either causes or constitutes your overall well-functioning, in some dimension of life.

${ }^{15}$ If we generalize the instrumental relation to include the constitutive one, then there are cases where claims about means are tautologies, namely where there is a necessary constituent. It is a tautology that your vote is needed if the end is $100 \%$ voter turnout, say. Some philosophers also think that performing an action is, tautologously, a means to the performance of that action. 
So does this mean that I am after all suggesting that there is no difference between the final use of 'good for you' and the motherly use of 'good for you,' no difference between what Alfred's mother is saying when she says broccoli is good for him and what we are saying when we say that getting the position is good for him? Not quite. What I am suggesting is that the final sense and the motherly sense of 'good for you' mention the same set of facts, but from two different perspectives. From one of these perspectives, we view Alfred as a functional system, that is, an entity whose parts and lesser systems all contribute to the achievement of some end or ends, in some cases simply to the maintenance or continuation of that functional system itself. From the other, we view the things that are good for Alfred from Alfred's own point of view. It is because these two perspectives can come together that there is such a thing as the good. Let me explain.

\section{Goodness and Functional Systems}

The association of the idea of the good with the idea of a functional system goes back at least to Plato and Aristotle. To say that something is a good X, they believed, is to say that it has the properties that enable it to perform its function well. ${ }^{16}$ Here we are using 'good' in an ordinary evaluative sense: a good knife is sharp; a good car is safe and gets good gas mileage; a good teacher is patient and attentive; a good watchdog is fierce and loyal. A living thing just as such may also be viewed as a functional system, as Aristotle taught us: we can view its function as a kind of self-maintenance, or survival and reproduction, or as

\footnotetext{
${ }^{16}$ For Aristotle, see especially Nicomachean Ethics 1.7; for Plato see Republic Book I, 352d$354 \mathrm{~b}$.
} 
leading the life characteristic of its kind. We are viewing the living thing as that kind of functional system when we evaluate its condition as healthy or not.

But it is not merely the case that functional systems are the sort of thing that can be evaluatively good or bad; it also appears to follow from the way in which functional systems can be good or bad that things can be good or bad for them, in the motherly sense. Being driven once in a while is good for a car, while low-quality gasoline is bad for it. Earthworms and rain are good for the soil, and fresh air and exercise are good for both you and your dog. If something is a functional system, the properties that enable it to perform its function well are the properties that make it a good one, and the conditions that tend to promote and protect those properties are good for it. So functional systems, by their very nature, have a good. They have a good in the motherly sense of having a good - the sense in which broccoli is good for Alfred. Now recall that I said that the motherly sense could be extended to talk about things that affect a person or an animal's psychological health, or a person's moral and spiritual condition. When we say, 'you have been so successful, it is really good for you to be taken down a peg now and then,' are we thinking of the person as a functional system? I think we are. The implication is that the build-up of self-satisfaction may eventually clog the person's moral arteries so much that it will interfere with his ability to keep on doing as well as he has.

If the idea of being good for something is linked to the idea of a functional system, where does the idea of a functional system come from? Does it name something we encounter in experience, a substance like water or a property like blue? It would seem not, for the idea is too deeply rooted in the way we see the world for that. I cannot treat this topic properly here, but let me gesture at the very large issues that I have in mind. Aristotle 
thought that for a thing to be unified in the way that a thing has to be unified in order to count as a thing at all - that is, an ousia (oúoía), or a substance - is for it to be a kind of functional system. ${ }^{17}$ This makes the idea a basic metaphysical one. In the Critique of Judgment, Kant suggests, speaking a bit roughly, that the exercise of reflective judgment - the kind of judgment we use to form concepts of the kinds of things that there are, as opposed to the kind we use to place objects under concepts we already have - anyway, reflective judgment, or concept formation, involves interpreting some things as functional systems within the manifold of experience. Kant's idea is really the same as Aristotle's, with the characteristic Kantian twist of making the principle of substantial unity, functional unity, one that emanates outward from us rather than one that we encounter in nature. ${ }^{18}$ If these ideas are right, then the idea of a functional system is roughly what Plato called the Form of the Good, the organizing principle at the basis of all objects or of our ways of conceptualizing them. Except, of course, for the fact that something is not good absolutely simply by virtue of being a functional system, even a functional system that is good or perfect of its kind. After all, a nuclear bomb or an assassin may be perfect of its kind. But a functional system is still the form of something, if what I've just said is right - it is the form of having a good.

\footnotetext{
${ }^{17} \mathrm{I}$ defend this claim in 'Aristotle's Function Argument' in Christine M. Korsgaard, The Constitution of Agency (Oxford: Oxford University Press, 2008).

${ }^{18}$ For further discussion, see Christine M. Korsgaard, Self-Constitution: Agency, Identity, and Integrity (Oxford: Oxford University Press, 2009), chapter 2.
} 


\section{Goodness and Agency}

Now that's still having a good in what I have been calling the motherly sense - the sense in which 'good for you' means something like 'enables you to function well.' So now I'm going to switch from calling that good for you in the 'motherly' sense to calling it good for you in the 'functional sense.' Something is good for you in the functional sense if it maintains, promotes, or enhances your functioning. In order to get at 'good for you' in the final sense, we need to talk about another way in which we use the concept of the good. In my paper, 'Realism and Constructivism in Twentieth-Century Moral Philosophy,' I argue that we use normative concepts to mark out schematically the solutions to certain kinds of problems which we have to solve. ${ }^{19}$ I take my cue from John Rawls, who argued that we use the concept of 'justice' to mark out the solution to the problem of how the benefits and burdens of social cooperation are to be distributed. 'Justice' is our word for whatever solves that problem, and philosophers who argue about what justice is are arguing about how that problem ought to be solved. $^{20}$

Now the fact that we are reflective agents who do not automatically do what desire and instinct prompt us to do also confronts us with problems. For as a reflective agent, you cannot treat the bare fact that something attracts you as a reason to try to go for it without further ado. Nor can you treat the fact that an act would promote some end you've decided to go for as settling the question what you should $d o$, for the act that promotes your end might not be, in various ways, worth it. There might be prudential or moral costs. So we

\footnotetext{
${ }^{19}$ In Korsgaard, The Constitution of Agency.

${ }^{20}$ Among other things, this solves the problem about what philosophers who define justice completely differently are disagreeing about.
} 
have to have some way of making these decisions, some procedure or principle to follow. These two problems are the problems of the good and the right respectively - the problem of what to go for, and the problem of what to do. They are not of course completely independent, because you cannot actually decide to go for something without first deciding that that there's some way of going for it - that is, some act that would promote or achieve it - that you might conceivably find it worth deciding to do. ${ }^{21}$ But of course you also cannot even generate some candidate actions to consider without first settling on some things you might like to go for. So insofar as we are agents, we are faced with these two interlocking problems. I want you to keep in mind that the two problems are interlocking, because that will matter later on.

Why do we use the same word - 'good' - when we are talking about the success of functional systems and when we are talking about the things we've decided to go for? There seems to be a curious sort of interdependence between two ideas at work here, the idea of a functional system and the idea of an agent. When we regard an object as a functional system, we are regarding it rather as if it were a kind of agent, and the purpose that it serves as if it were an end that it had decided to go for. It is as if behind our division of the world into objects lurked a form of primitive animism, a determination to view the world as being full of agents like ourselves.

\footnotetext{
${ }^{21}$ That is what Kant called 'the paradox of method' and Rawls called 'the priority of the right'. For Kant, see The Critique of Practical Reason (translated by Mary Gregor for Cambridge: Cambridge University Press, 1997), 5:63; for Rawls, A Theory of Justice (Cambridge, MA: Harvard University Press, $2^{\text {nd }}$ ed., 1999), 27-28.
} 
But then again, when we view ourselves as agents, we view ourselves in turn as functional systems. ${ }^{22}$ For to be an agent is to be essentially subject to a standard of success and failure, and to be subject to a standard of success and failure in the very same way that a functional system is. Here's what I have in mind. A functional system - let's say a machine - is designed to achieve a certain end. If it does not achieve its end, we say that it has failed. You were late this morning, you say, apologetically, because your alarm clock broke down and failed to go off. But to be successful, it is not enough that your alarm clock goes off from any cause whatever. If the alarm rings because a sudden jolt of electricity happens to break a spring which accidentally hits the mechanism that sets off the alarm at 7:00 a.m. precisely, it is not a good clock. A functional system, to be successful, has to be the kind of thing that reliably achieves its end.

In the same way, the kind of success that we associate with agency is not exhausted by the idea of the agent actually bringing the end about, since an agent who brought about his end only accidentally - say by a deviant causal pathway - would have failed as an agent. If I fire my gun wildly astray, but the bullet ricochets off a cast iron fence and happens to hit the target in exactly the spot that I intended, I have not made a good shot. Indeed, once I understand the causal situation, I should feel that I have been the beneficiary of a lucky accident, that is: that $I$ didn't really do anything at all. To be successful in action is not merely

\footnotetext{
${ }^{22}$ The remarks that follow are borrowed from 'The Normative Constitution of Agency,' (forthcoming in Rational and Social Agency: Essays on the Philosophy of Michael Bratman, ed. Manual Vargas and Gideon Yaffe (New York: Oxford University Press), \$1.3.
} 
to do something that brings about your end. To be successful in action is to make yourself into the kind of thing that reliably achieves that end. ${ }^{23}$

So to regard yourself as an agent is to regard yourself as a functional system, and to regard yourself as a functional system is to regard yourself as having a good, in the functional sense of good. But now it is not only the functional sense of good. For if you regard the thing you aim at as a final good - that is, as something worth going for - then you regard the things that promote it, your own condition included, as good in that way too. An agent necessarily values his own efficacy, and therefore necessarily values his own functional good as an aspect of his final good.

6. Why Some Things Have a Good in the Final Sense ${ }^{24}$

One more step is necessary. When we regard an organism as a functional system, we regard its end as being, as I said earlier, something along these lines: to maintain itself, to survive and reproduce, or to live the life characteristic of its kind. The end of an organism is,

${ }_{23}$ Our self-consciousness about our agential success and failure is thus the source of the first primitive normative thoughts that leads us to the idea of well-functioning and from there to normative thought more generally. Notice the close tie this provides between normative thought and the first-person perspective. And notice too that a failure of efficacy is not the only route to the idea of a failure of one's agency; a failure of autonomy provides another such route. See Self-Constitution, \5.1. I am indebted here to discussion with Alan Code.

${ }^{24}$ For another version of the argument of this section, see 'The Origin of the Good and Our Animal Nature', forthcoming in Problems of Goodness: New Essays on Metaetbics, edited by Bastian Reichardt. 
in a sense, simply to be and to continue being what it is, or as I have put it elsewhere, to constitute itself. ${ }^{25}$

Now if the organism is an agent - roughly speaking, an animal or a person - the way that she constitutes herself is in part by having conscious states that track, at least roughly and defeasibly, what is good or bad for her in the functional sense. An animal that has any chance of surviving must feel hungry when she needs food, fear in the face of predators and threats, and pain in the face of conditions that are damaging to her. She must perceive what is good for her in the functional sense as attractive and what is bad for her in the functional sense as aversive, and those perceptions must determine what she decides to go for and what to avoid. ${ }^{26}$ If the organism is a rational agent, then she will do some of this consciously, using the word 'good' to designate the things that are good for her in the functional sense when she decides to go for them. She conceives the things that are good for her to be good things in the final sense, and as such she decides to go for them.

Before I said that the motherly or what I am now calling the functional sense of good for you and the final sense of good for you name the same set of facts from two different perspectives. In one, we view the entity as a functional system and in the other, we view the things that are good for the entity from the entity's own point of view. I have now explained why that is so. Animals perceive, and rational animals also conceive, what is good for them as something to go for, and so as what is good for them in the final sense too. What is

\footnotetext{
${ }^{25}$ Korsgaard, Self-Constitution, especially $\$ 2.2$.

${ }^{26}$ Korsgaard, Self-Constitution, \$6.1.2.
} 
functionally good for them, in the broad sense I have been describing, is also good from their point of view, and so is their final good. ${ }^{27}$

Now let me avert some possible confusions. First, I am not claiming that anything that seems good from your point of view is therefore actually good for you, in either the functional or the final sense. We are highly imperfect functional systems, and therefore we can get it wrong: what seems good to us may not be good for us after all. Importantly, because you are a functional system that works by tracking your own good through perception and thought, when you do get it wrong you are malfunctioning. The very fact that you don't know what's good for you is, in a way, a large part of what is wrong.

Second, I am not claiming that the final good for people is survival and reproduction, or simple self-maintenance, or even to lead a healthy life of our kind. That is, I am not claiming that, unless we take a capacious view of what is involved in selfmaintenance, or in leading a healthy life of our kind. For first of all, recall that I have argued that even the functional sense of good-for extends to things that both promote and constitute our psychological, moral, and spiritual health as well as our physical health. Second (or maybe this is the same), elsewhere I have argued that the human project of selfconstitution involves the adoption and maintenance of what I call 'practical identities,' 'the roles and relationships in terms of which we value ourselves and find our lives worth living and our actions worth undertaking. ${ }^{28}$ For us, the functional sense of good-for and therefore ${ }^{27}$ Notice an important consequence of this story: valuing is prior to value. It is because there are things that necessarily strike agents as things to go for, that there are final goods. ${ }^{28} \mathrm{I}$ introduce the notion of practical identity in The Sources of Normativity, 101. For further discussion, see Self-Constitution, \$1.4. 
the final sense too will include whatever promotes and constitutes our practical identities. ${ }^{29}$ Formally speaking, my view is a rather obvious one: that the human good is being able to make something valuable or worthwhile of ourselves. ${ }^{30}$

Nor, thirdly, am I saying that the things that promote and constitute our practical identities are good only because they promote and constitute our practical identities, and so only good in a vaguely instrumental sense. That would be the same mistake as thinking the things that promote and constitute health are instrumental because they promote survival. Like health, the successful maintenance of our practical identities is the excellence of our lives. The things that promote and constitute the maintenance of our practical identities are final goods because as self-constituting beings, we see them as things to go for.

\section{The Problem Cases}

I have argued that having a good cannot just be a matter of standing in a special relation to something that is, as it were, already, independently good. Just as nothing counts as a hand unless it is related to the nervous system of an animal in a quite particular way, so nothing counts as a good until it is related to an agent in a quite particular way. An animal

${ }^{29}$ This is why 'final' isn't a great word here (see note 12): because this sense of good also encompasses the things that promote the things we decide to pursue for their own sakes.

${ }^{30}$ That is, the human good is carrying out the particularly normative form of selfconstitution particular to our kind, the rational kind. What gives content to 'valuable' here? First, in Self-Constitution I argued that morality is necessary for successful self-constitution. I also describe the way thoughts about value more generally can get a footing in SelfConstitution, \$10.1.4. 
whose nervous system makes it possible to wiggle his fingers without manipulating them externally has a hand. An entity whose functional organization involves her tending to that very functional organization, that is, looking after it, through action, has a good, in the final sense of good. These claims are parallel: hands and final goods are artifacts of these relationships.

On this account, what most obviously has a good are individual people and animals. Since those are the things that most obviously have a good, I take that to be a virtue of the account. We can now have many arguments about what sorts of things count as agents and what would be good for them. But according to my account everything that has a good is an agent, and everything good is, necessarily, some agent's good. This brings us back finally to the problem cases I mentioned at the outset. It seems hard to explain why we are tempted by the idea that a universe full of happy people and animals is better than a universe full of miserable ones, since if the people and animals involved in the two cases are different people and animals, then there is no one for whom it is better. It seems hard to explain why we are tempted by the idea that a society in which wealth is distributed more equally is better, since although it is plainly better for some people, who would otherwise be poor, it is also plainly worse for others, who would otherwise be rich. Obviously these are not the only problem cases. But I will end by discussing these two cases, to give you a sense of how I think we should handle these issues.

As I mentioned early on, one way to approach the problem of the two universes would be to try to make it out that the universe is itself the kind of agent for whom things can be good or bad. Then perhaps it is better for the universe if it is full of happy people and animals than if it is full of miserable ones? During his science television series Cosmos, Carl 
Sagan at one point suggested rather impressively that humanity represents the way in which the universe comes to know itself. ${ }^{31}$ It's a pretty thought, although I'm not sure a Kantian can accept it. But never mind that. Could the idea that we somehow count as the consciousness of the universe give us grounds for thinking of the universe as an agent for whom things can be good or bad?

Obviously there are some difficulties here. One is that even if we did think so it is not clear why it would be better for the universe to be full of happy people and animals, unless we also think its function is to support happy life. ${ }^{32}$ More importantly, though, when we have the thought that the universe full of miserable life is not as good as the universe full of happy life, it is not because we are sympathizing with the universe. It is because we are sympathizing with the people and animals who are in the universe, and we find the thought of their happiness pleasing. In fact, that in itself is already part of the explanation of why we tend to think that the universe full of happy life is better. For you should notice that on the account of the good that I have given, sympathy plays an essential role in the way the concept functions. According to my account, we arrive at the idea of the final good when we look at the world in the way that a certain kind of entity - one that functions by tracking its own functional good through perception and thought - looks at the world. That means that any thoughts I have about what is good for you are essentially sympathetic. But it is not that we are pleased when we sympathize with happy people and animals because we believe independently of sympathy that their happiness is a good thing. If we believed that, we

\footnotetext{
${ }^{31}$ Quoted on the Carl Sagan website at http://www.carlsagan.com/.

${ }^{32}$ Sagan's idea that we are the consciousness of the universe would explain the temptation to think that, I suppose.
} 
could be pleased by it without the aid of sympathy. Rather, they necessarily regard their happiness, or more properly speaking the conditions that constitute it, is as something to go for, something worthy of pursuit. And then when we sympathize with them, we regard their happiness, and the things that constitute, that way too. ${ }^{33}$ That's why we see it as good. ${ }^{34}$

The larger point I am trying to make here is that we cannot completely divorce thoughts about the good from thoughts about what to go for, given that the original home of the concept is, so to speak, in the deliberative standpoint. That's why I asked you to keep in mind, earlier, the way in which the problems named by 'the right' and 'the good' are interlocking. For I think we will find the answer to the question we are asking now in that fact.

When we think about the comparison between the goodness of two universes, it is impossible not to import thoughts about which of the two we would bring into existence were we in the position of the creator and therefore faced with that choice. If we were, I think we all agree, we would certainly bring into existence the universe full of happy people and animals if we could. But that's not because it contains more happiness and happiness is impersonally good. It's because if you are the creator, then it is right, that is, it is your duty, to do as well as you can for whomever you create. So the universe full of happy people and animals is not exactly more worthy of choice because it is better. Rather, it is better - and

33 The 'or rather, the conditions which constitute it' is there because I am among those who don't believe that people characteristically pursue happiness. I believe we pursue projects we think are worthwhile, and are happy when we are succeeding in promoting or realizing those projects. Saying that people pursue happiness is, at best, shorthand.

${ }^{34}$ This is another manifestation of the fact that valuing is prior to value. 
yes, in my view we do get that conclusion - because it is more worthy of choice. But this is not to say that there is no one for whom it is better, and that no thought of the good guides the choice. The happier universe is better for whoever gets created. But in order to explain why 'whoever gets created' is the right way to single out the beneficiary of the choice in this case, we have to appeal to the deliberative context in which the choice is made, including any duties inherent in that deliberative context.

When we are deciding to have children or enacting legislation that will affect population, we are also in the position of a creator. That is why it makes perfect sense to say, for instance, that it will be better to have a child later when you are in better circumstances, even though there is no genetically identifiable child for whom that is better. Your duty as a prospective parent is to do as well as you can for whatever child you have, not for some genetically identifiable individual who does not yet exist and may never do so. Notice also that Parfit's famous repugnant conclusion - the conclusion that we must keep adding to the population until the conditions created by the crowding destroy the value of life, making it not worth living - is blocked by these arguments. ${ }^{35}$ The world is not better with more total happiness in it, because there is no one for whom it is better, nor do we owe it to non-existent people to bring them into existence so that they can have a little fun. Our

${ }^{35}$ Parfit first introduced the Repugnant Conclusion in chapter 17 of Reasons and Persons (Oxford: Clarendon Press, 1984). The argument in the text bears generally against puzzles arising from the 'non-identity' problem - cases in which we can apparently do better by producing a better state of affairs for a genetically different individual. These cases may be thought to support the idea of impersonal goods. I am arguing instead that it is not always right to identify the beneficiaries of action in terms of their genetic identities. 
duty, when we are settling population policy, is to the future inhabitants of the planet, whoever they are.

As for equitable distributions, there are two important things to say about them, but they come to the same thing. The first is modeled exactly on what I said about the two universes. More equitable distributions, like universes full of happy people and animals, are better because they are more worthy of choice, in the context in which one chooses a system of distribution, which is when one is setting up a basic structure for society. In order to learn why the more equitable distribution is more worthy of choice, all you have to do now is read John Rawls's Theory of Justice, to find out why in these circumstances, a more equitable distribution is the one that would be chosen. ${ }^{36}$ Here, as in the case of the two universes, the choice is governed by thoughts about what is better for someone. First, the parties in the original position make the choice asking what, under the veil of ignorance, will be better for themselves. But that is only a step along the way. The more important point is that we readers who make the thought experiment of entering the original position are undertaking to make the choice in the way that will be best for a citizen of a liberal society considered merely as such. Again, the context of the choice explains why that is the beneficiary we should be thinking of in this kind of case.

\footnotetext{
${ }^{36}$ In fact, the reason why I keep using 'more equitable' rather than 'equal' is because I think a distribution according to Rawls's difference principle (the principle of choosing the distribution that is the best for the worst off) is preferable to a strictly egalitarian one. See $A$ Theory of Justice, Chapters 2 and 3.
} 
The other thing to say is that the political state, unlike the universe, is a kind of agent - indeed, according to my own arguments in Self-Constitution, a self-constituting one. ${ }^{37} \mathrm{We}$ might think that there are all kinds of ways in which the state, considered simply as such, is better off if there are more equitable distributions. More equitable distributions support a middle class, with all the benefits to stability and culture that a middle class is supposed to provide. In the end, I think that this comes to the same thing, though. The benefits of stability and culture ultimately accrue to the citizen, considered just as such. In both arguments, the beneficiary of the state is the representative citizen, and we look to what is good for her. But the reason we do so is because it is to her that the arrangements of the state must be justified, and not to some genetically identifiable individual. The state has no good of its own that is not the good of the representative citizen.

This is not to say that there are not other kinds of collective agents that do have such a good, say, corporations or universities or clubs. But it is a particularly important point to make about the state. The state's interests can come into conflict with yours, considering you as a private individual. But it cannot come into conflict with yours, considering you as a representative citizen. That there should be occasion to sacrifice the citizen for the good of the state is a logical impossibility.

\section{Conclusion}

In this paper I have argued that the concept of someone's having a good is prior to the concept of something's being good - just as the concept of having a hand is prior to the concept of something's being a hand. An agent is the sort of thing that has a final good,

\footnotetext{
${ }^{37}$ See Self-Constitution, Chapter 7.
} 
because an agent necessarily regards her own well-functioning as something to go for. I think it follows that everything that is good in the final sense must be good for someone. Using the case of the two universes, I've tried to indicate how I would handle cases in which our intuitions might seem to be ones that we can explain only by appeal to impersonal goods. What's really happening in these cases is not that we are appealing to impersonal goods, but rather that the designation of the relevant beneficiaries is given by the nature of the choice that is being made. Where there was really no choice between the universe full of happy inhabitants and the universe full of miserable ones, there would be no fact about which one was better - but then, because the question raised by the concept of the good is the question what to do go for, there would also be no occasion for making the judgment. I believe that these arguments vindicate the existential claim I started out from: the only reason why anything matters is because the world contains entities for whom things can be good or bad. ${ }^{38}$

${ }^{38}$ This paper was delivered as the The Royal Institute of Philosophy Lecture in March 2012, Suarez Lecture at Fordham in April 2013, and as one of the Agnes Cumin Lectures at University College Dublin in March. I am indebted to audiences for helpful discussion on all of these occasions and at colloquia at Stanford, the CUNY Graduate Center, SUNYBinghamton, Brandeis, and the Georg-August University in Göttengen. 